\title{
Probiotics in inflammatory bowel disease: is it all gut flora modulation?
}

\section{S Ghosh, D van Heel, R J Playford}

\section{Understanding probiotic action may permit modulation of the immune system, both locally and systemically}

\footnotetext{
$\mathrm{T}$
} here is considerable public, media, and scientific interest in "natural" products, including probiotics, in modulating intestinal inflammation and health. ${ }^{1}$ Intestinal microflora are intimately involved in the generation of immunocompetent cells and tuning the balance between $\mathrm{T}$ helper $\mathrm{l}\left(\mathrm{Th}_{\mathrm{l}}\right)$ and $\mathrm{Th}_{2}$ immunity during the development of the gut associated immune system. It is now generally accepted that the intestinal bacterial flora contributes significantly to the pathogenesis of inflammatory bowel disease (IBD) along with mucosal immune dysregulation and genetic susceptibility. Considerable research is focused on modifying the intestinal flora with probiotic bacteria to attenuate inflammatory activity and prevent relapses in ulcerative colitis, Crohn's disease, and pouchitis. Although both Lactobacillus species and Bifidobacterium species are frequently used, the optimum use of probiotics in IBD requires greater understanding of their effects on the immune system.

A rationale for the use of probiotics in IBD stems from reports of dysbiosis in the intestinal flora in ulcerative colitis, Crohn's disease, and pouchitis, either by conventional anaerobic culture or by analysis using molecular probes. It is however unclear whether such alterations in intestinal flora drives the inflammation or is a consequence of it. The practical application of probiotic strategy has been especially encouraged by the positive results of a trial in its use for the prevention and treatment of pouchitis. ${ }^{23}$ The multispecies probiotics used pose special challenges in identifying precise mechanism of action, although alterations in faecal flora have been demonstrated. ${ }^{4}$ Despite some positive trials, generalisation from pouchitis to their use for all forms of IBD appears somewhat premature, however, as for example, a trial of administration of Lactobacillus $G G$ after surgical resection for Crohn's disease proved ineffective in preventing relapse. ${ }^{5}$ Further studies are therefore required in ulcerative colitis and Crohn's disease before firm recommendations may be made.
Lactobacilli are a major constituent of the intestinal microflora and are frequently used as probiotics, often in the health food industry. ${ }^{6}$ Among the Lactobacillus genus, different species of bacteria induce distinct mucosal cytokine profiles in the gut immune system of BALB/C mice. ${ }^{7}$ For example, an increase in the $\mathrm{Th}_{2}$ cytokines interleukin (IL)-10 and IL-4 was observed in mice fed Lactobacillus delbrueckii subspecies Bulgaricus and Lactobacillus casei whereas, in contrast, a significant induction of the $\mathrm{Th}_{1}$ cytokines IL-2 and IL-12 was observed with Lactobacillus acidophilus. It is therefore important that notice is taken of which specific bacteria are being used.

Various knockout, transgenic, and adoptive transfer murine and rodent models of IBD have been generated and the requirement for bacterial colonisation to induce a IBD phenotype is virtually universal, despite the complexities of the immune network. ${ }^{8}$ In contrast, in the IL-10 knockout mice model of colitis, probiotic therapy with Lactobacillus species and Bifidobacterium species has been shown to be effective in reducing inflammation. ${ }^{9}{ }^{10}$ In animal models, probiotic therapy may prevent relapses of colitis, as shown by treatment with Lactobacillus GG in HLA-B27 transgenic rats after antibiotic treatment. ${ }^{11}$ It is therefore clear that not all bacteria have the same actions on gut immune function. Separating them into "good" and "bad" bacteria, a marketing strategy often used in the commercial industry, is however a gross oversimplification, and takes no account of host differences as a contributory factor.

In this issue of the Gut, researchers from Cork, Ireland, ${ }^{12}$ challenge the conventional hypothesis of mechanisms of probiotic efficacy by administering Lactobacillus salivarius subcutaneously to IL-10 knockout mice [see page 694]. The anti-inflammatory effect of subcutaneous administration was not specific as it was also seen in a murine model of arthritis. Non-viable bacteria could not be tested as the group receiving heat treated L salivarius had $100 \%$ mortality by week 10. No change in faecal microflora occurred as a result of this subcutaneous administration of $L$ salivarius, suggesting a mechanism of action distinct from colonic floral modulation. Various indicators of altered immune function were seen with decreased tumour necrosis factor (TNF) and IL-12 levels being obtained from splenocytes that had been stimulated by Salmonella typhimurium. In contrast, transforming growth factor (TGF)- $\beta$ levels were maintained. Such systemic anti-inflammatory activity is counterintuitive to a simplistic model of gut flora modulation, and leads to speculation about the molecules involved in driving immunomodulation.

The findings of the current study are not the first to suggest that probiotics have more than a local anti-inflammatory effect by modulating the flora. For example, Lactobacillus casei or Lactobacillus bulgaricus reduced the inflammatory response induced by coculture of bacteria with mucosal explants from Crohn's disease affected intestinal tissue. In this study, a significant reduction of proinflammatory cytokines such as TNF was noted..$^{13}$ Such anti-inflammatory effect might even be systemic, as shown by the bacteria CpG DNA experiments discussed later.

Probiotics may also influence mucosal cell-cell interactions and cellular "stability" by actions such as enhancement of intestinal barrier function by modulating cytoskeletal and tight junctional protein phosphorylation. For example, live probiotics such as Lactobacillus acidophilus or Streptococcus thermophilus protect in vitro intestinal epithelial cell lines (HT29, Caco-2) from pathogen invasion and adhesion by enteroinvasive Escherichia coli. ${ }^{14}$ Similarly, the nonpathogenic $E$ coli strain Nissle 1917 inhibited adhesion and invasion of intestinal epithelial cell line (intestine 407 ) by adherent invasive $E$ coli strains isolated from patients with Crohn's disease. ${ }^{15}$

In "the age of the genome", it is not surprising that much time and attention has been spent on studying the importance of the detailed bacterial DNA sequences in these effects. Bacterial DNA contains non-methylated CpG motifs which bind to toll-like receptor 9 (TLR-9). TLR-9 signalling is dependent on the adaptor protein MyD88. Such immunostimulatory DNA sequences (ISS-DNA or CpG DNA) of bacterial origin have been shown to reduce inflammation in rodent IBD models such as DSS induced colitis, hapten induced colitis in BALB/C mice, and the IL-10 knockout mice model of colitis. This reduction in inflammation was accompanied by inhibition of 
proinflammatory cytokine and chemokine production and suppression of induction of matrix metalloproteinases in the colon. ${ }^{16}$

Further evidence of the central role of bacterial DNA has come from novel experiments where both intragastric and subcutaneous administration of probiotic and $E$ coli DNA attenuated the severity of DSS induced colitis. ${ }^{17}$ The form that this DNA takes appears crucial, as methylated probiotic DNA, calf thymus DNA, and DNAse treated probiotics were ineffective.

Given this complexity, do we need live bacteria, dead bacteria, or just the DNA? Unfortunately, the data are confusing and sometimes contradictory. TLR-9 and the adaptor protein MyD88 appear essential in signalling, and in their presence even non-viable bacteria can signal. In TLR-9 deficient mice, unlike TLR-2 or TLR-4 deficient mice, intragastric $\gamma$ irradiated (that is, non-viable) probiotics had no effect on DSS induced colitis. Mice deficient in MyD88 did not respond to $\gamma$ irradiated probiotics. ${ }^{17}$ The immune modulatory function of DNA has also been demonstrated in a study of peripheral blood mononuclear cells from healthy donors where Bifidobacterium genomic DNA caused induction of secretion of the antiinflammatory IL-10. ${ }^{18}$ Given the high GC content of Bifidobacterium chromosomal DNA, it will be of interest to assess the effect of its subcutaneous administration in the IL-10 knockout model of colitis.

The immune modulatory properties of the various probiotic bacteria may differ, and this becomes problematic for the use of multispecies preparations. Furthermore, not all immunostimulatory oligonucleotides have the palindromic CpG motif. In one study, chromosomal DNA was purified from nine strains of Lactobacillus delbrueckii subspecies Bulgaricus and six strains of Streptococcus thermophilus derived from yoghurt starter cultures. Only DNA from L bulgaricus NIAI B6 induced significant proliferation of mice Peyer's patch and splenic B cells although it did not contain a palindromic CpG motif. ${ }^{19}$ It is therefore clear that "the devil is in the detail" and extrapolation across DNA sequences and bacterial species may provide false impressions.

In addition to indirectly influencing gut flora and stimulating immune responses, the probiotic strains themselves produce antimicrobial peptides. Bacteriocin production is often associated with probiotic strains, and Lactobacillus salivarius cultures produce a broad spectrum bacteriocin that exhibits activity against a range of microorganisms such as Bacillus, Staphylococcus, Enterococcus, and Listeria species. Bacteriocins are synthesised in ribosomes as prepeptides before being released extracellularly, and their genetic locus in Lactobacillus salivarius has been identified. ${ }^{20}$ Production of different classes of bacteriocins confers a competitive survival advantage in colonisation and therefore these molecules are most relevant within the intestinal flora, but their systemic effects require further study. Importantly, the production and activity of bacteriocin is not affected by spray drying which may facilitate commercial preparation. $^{21}$

There has recently been much interest in the function of dendritic cells (DC) in controlling gut immune activity. DC act as the switch that determines the delicate balance between $\mathrm{Th}_{1}$ and $\mathrm{Th}_{2}$ immunity, as well as tolerance $\left(\mathrm{Th}_{3}\right)$. Therefore, it is likely that the DC phenotype and state of activation determine whether initiation of immunity or tolerance takes place and DC are likely to play a central role in mediating the effect of probiotic bacteria and determining the type of immune response that occurs. Different species of lactobacillus exert different DC activation patterns and the complexity of such interactions is exemplified by demonstration that Lactobacillus reuteri, a poor inducer of IL-12, is capable of inhibiting DC activation by other Lactobacillus species. $^{22}$ The threshold of bacterial concentration necessary to induce cytokine production may be different for proinflammatory cytokines IL-12/TNF and anti-inflammatory/regulatory cytokine IL-10, permitting fine modulation of the immune response. ${ }^{22}$

Evidence of probiotic strains affecting $\mathrm{Th}_{1} / \mathrm{Th}_{2}$ immune balance also comes from experiments in which stimulation of macrophages with Lactobacillus rhamnosus GG induced mRNA expression of the chemokines CCL2, CCL3, CCL5, CCL7, CCL19, CCL20, CXCL8, CXCL9, and CXCL10. ${ }^{23}$ Such a $\mathrm{Th}_{1}$ pattern of chemokine induction could explain the proposed antiallergenic properties of this probiotic strain and may benefit $\mathrm{Th}_{2}$ oriented ulcerative colitis. Interestingly, studies of oral administration of these bacteria suggest that they may affect the systemic immune response. For example, oral administration of Lactobacillus rhamnosus $G G$ to healthy volunteers for five weeks affected the systemic cellular immune response to intestinal microorganisms. ${ }^{24}$

What about the host? Identification of NOD2 mutations associated with Crohn's disease provides further support for the central role of bacteria in the pathogenesis. ${ }^{25} 26$ Three NOD2 mutations located near or in the leucine rich repeats involve a frameshift mutation
(Leu 1007fsinsC) or two missense mutations (Gly908Arg and Arg702Trp). These alterations are associated with increased risk of development of Crohn's disease and result in defective induction of nuclear factor $\kappa \mathrm{B}(\mathrm{NF} \kappa \mathrm{B})$ activation by bacterial peptidoglycan and muramyl dipeptide (MDP). MDP induced activation of NFKB in mononuclear cells is absent in patients with Crohn's disease homozygous for the Leul007fsinsC mutation. ${ }^{27} 28$ It is therefore interesting to speculate that NOD2 mutations associated with Crohn's disease result in defective sensing of some bacteria which may precipitate inappropriate diffuse activation of NFKB and inflammation through non-NOD2 mechanisms. Repeating the experiments with Crohn's mucosal explants ${ }^{13}$ from patients with homozygous, heterozygous, and double heterozygous NOD2 mutations, and appropriate controls cocultured with Lactobacilli, may provide interesting data using TNF readouts.

Our attempts to understand how bacteria modulate the immune system will undoubtedly yield novel therapeutic targets and therapeutic agents. Irrespective of whether or not dysbiosis is reproducibly confirmed in IBD, we need to consider probiotic therapy in terms of specific molecules modulating defined targets in the gut mucosal and systemic immune system, and move

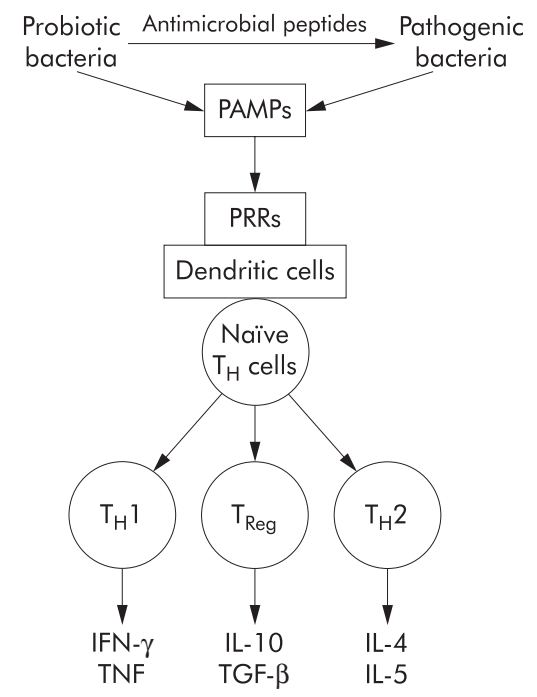

Figure 1 Pathogen associated molecular patterns (PAMPs) derived from bacteria (including probiotics) are recognised by pattern recognition receptors (PRRs, such as Toll-like receptors). Initiation of dendritic cell (DC) maturation starts after ligation of PRRs, which also requires adaptor proteins such as MyD88 for signalling. Type of PAMPs determines the selective priming of DCs for production of $T_{H} 1$, $\mathrm{T}_{\mathrm{H}} 2$, and $\mathrm{T}_{\text {Reg }}$ lymphocyte polarising factors. Different PAMPs ligate to specific corresponding PRRs. IL, interleukin; TNF, tumour necrosis factor; TGF- $\beta$, transforming growth factor $\beta$. 
away from a simplistic concept of repopulating the intestinal flora with "friendly" bacteria. Bacteria are only "friendly" in the context of the desired immune modulation required for a specific disease. The environment to which the immune system is exposed to determines DC phenotype and state of activation and eventually drives the balance between effector and regulatory $\mathrm{T}$ cells (fig 1). Understanding probiotic action may permit modulation of the immune system, both locally and systemically. The article by sheil and colleagues $^{12}$ is the right step towards stimulating further research where immunologists, microbiologists, and gastroenterologists can collaborate.

Gut 2004;53:620-622.

doi: 10.1136/gut.2003.034249

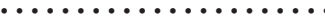

Authors' affiliations

S Ghosh, D van Heel, R J Playford,

Gastroentrology Section, Division of Medicine, Imperial College Faculty of Medicine,

Hammersmith Hospital, London, UK

Correspondence to: Professor S Ghoshlmperial

College London, Hammersmith Hospital,

Ducane Rd, London W12 ONN, UK ;

s.ghosh@imperial.ac.uk

\section{REFERENCES}

1 Ghosh S, Playford RJ. Bioactive natural compounds for the treatment of gastrointestina disorders. Clin Sci (Lond) 2003;104:547-6.

2 Gionchetti P, Rizzello F, Helwig U, et al. Prophylaxis of pouchitis onset with probiotic therapy: a double-blind, placebo-controlled trial. Gastroenterology 2003; 124:1202-9.

3 Mimura T, Rizzello F, Helwig U, et al. Once daily high dose probiotic therapy (VSL\#3) for maintaining remission in recurrent or refractory pouchitis. Gut 2004:53:108-14.
4 Venturi A, Gionchetti P, Rizzelo F, et al. Impact on the composition of the faecal flora by a new probiotic preparation: preliminary data on maintenance treatment of patients with ulcerative colitis. Aliment Pharmacol Ther 1999;13:1103-8.

5 Prantera C, Scribano ML, Falasco G, et al. Lactobacillus GG did not prevent endoscopic recurrence at one year nor reduced the severity of recurrent lesions. Gut 2002;51:405-9.

6 Ahrne S, Nobaek S, Jeppsson B, et al. The normal lactobacillus flora of healthy human rectal and oral mucosa. J Appl Microbiol 1988;85:88.

7 Perdigon G, Galdeano CM, Valdez JC, et al. Interaction of lactic acid bacteria with the gut immune system. Eur J Clin Nutr 2002:56/suppl 4):S21-6

8 Mizoguchi A, Mizoguchi E, Bhan AK. Immune networks in animal models of inflammatory bowel disease. Inflamm Bowel Dis 2003:9:246-59.

9 Madsen KL, Doyle JS, Jewell LD, et al. Lactobacillus species prevents colitis in interleukin 10 gene-deficient mice. Gastroenterology 1999:116:1107-14.

10 McCarthy J, O'Mahony L, O'Callaghan L, et al. Double blind placebo-controlled trial of two probiotic strains in interleukin 10 knockout mice and mechanistic link with cytokine balance. Gut 2003;52:975-980.

11 Dieleman LA, Goerres MS, Arendis A, et al. Lactobacillus GG prevents recurrence of colitis in HLA-B27 transgenic rats after antibiotic treatment. Gut 2003;52:370-6.

12 Sheil B, McCarthy J, O'Mahony L, et al. Is the mucosal route of administration essential for probiotic function? Subcutaneous administration is associated with attenuation of murine colitis and arthritis. Gut 2004;53:694-700.

13 Borruel N, Carol M, Casellas F, et al. Increased mucosal tumour necrosis factor alpha production in Crohn's disease can be downregulated ex vivo by probiotic bacteria. Gut 2002;51:659-64.

14 Resta-Lenert S, Barrett KE. Live probiotics protect intestinal epithelial cells from the effects of infection with enteroinvasive Escherichia coli (EIEC). Gut 2003;52:988-97.

15 Boudeau J, Glasser AL, Julien S, et al. Inhibitory effect of probiotic Escherichia coli strain Nissle 1917 on adhesion to and invasion of intestinal epithelial cells by adherent-invasive E.coli strains isolated from patients with Crohn's disease. Aliment Pharmacol Ther 2003;18:45-56.

16 Rachmilewitz D, Karmeli F, Takbayashi K, et al. Immunostimulatory DNA ameliorates experimental and spontaneous murine colitis. Gastroenterology 2002;122:1428-41.
17 Rachmilewitz D, Katakura K, Karmeli F, et al. Toll-like receptor 9 signalling mediates the antiinflammatory effects of probiotics in murine experimental colitis. Gastroenterology 2004; 126:520-8.

18 Lammers KM, Brigidi $P$, Vitali $B$, et al. Immunomodulatory effects of probiotic bacteria DNA: IL-10 and IL-10 response in human peripheral blood mononuclear cells. FEMS Immunol Med Microbiol 2003:38:165-72.

19 Kitazawa H, Watanabe H, Shimosato T, et al. Immunostimulatory oligonucleotide CpG-like motif exists in Lactobacillus delbrueckii ssp. bulgaricus NIAI B6. Int J Food Microbiol 2003:85:11-21.

20 Flynn S, van Sinderen D, Thornton GM, et al Characterization of the genetic locus responsible for the production of ABP-1 18, a nove bacteriocin produced by the probiotic bacterium Lactobacillus salivarius subsp. Salivarius UCC 118 Microbiology 2002;148:973-984.

21 Gardiner GE, O'Sullivan E, Kelly J, et al. Comparative survival rates of human-derived probiotic Lactobacillus paracasei and L. salivarius strains during heat treatment and spray drying. Appl Environ Microbiol 2000:66:2605-12

22 Christensen HR, Frokiaer H, Pestka JJ. Lactobacilli differentially modulate expression of cytokines and maturation surface markers in murine dendritic cells. J Immunol 2002; 168:171-8.

23 Veckman V, Miettinen M, Matikainen S, et al. Lactobacilli and Streptococci induce inflammatory chemokine production in human macrophages that stimulates Th cell chemotaxis. J Leukoc Biol 2003;74:395-402

24 Schultz $\mathrm{M}$, Linde $\mathrm{HJ}$, Lehn $\mathrm{N}$, et al. Immunostimulatory consequences of oral administration of Lactobacillus rhamnosus strain GG in healthy volunteers. J Dairy Res 2003:70: 165-73.

25 Ogura $\mathbf{Y}$, et al. A frameshift mutation in NOD2 associated with susceptibility to Crohn's disease. Nature 2001;41 1:603-6.

26 Hugot JP, et al. Association of NOD2 leucine-rich repeat variants with susceptibility to Crohn's disease. Nature 2001;411:599-603.

27 Inohara N, et al. Host recognition of bacterial muramyl dipeptide mediated through NOD2 implications for Crohn's disease. J Biol Chem 2003:278:5509-12.

28 Girardin SE, Travassos LH, Herve M, et al. Peptidoglycan molecular requirements allowing detection by Nodl and Nod2. J Biol Chem 2003;278:41702-8

\section{Fistulising Crohn's disease: MMPs gone awry}

\section{Schuppan, T Freitag}

\section{Broadening our understanding of the role of matrix metalloproteinases in Crohn's disease}

E istulae are a common complication of Crohn's disease (CD), and their most common perianal manifestation is present in $14-38 \%$ of CD patients in referral populations. ${ }^{1}$ Despite advances in conservative treatment, fistulae rarely heal, while surgical resection is effective but frequently does not prevent local recurrence or fistulising disease at other sites. ${ }^{1}$ Remodelling of the extracellular matrix (ECM) is a key event in chronic bowel inflammation, ${ }^{23}$ especially in CD which is characterised by both active fibrogenesis (that is, ECM production and deposition), leading, for example, to stricture formation, and by enhanced fibrolyis (that is, breakdown and removal of ECM), such as occurs in fistula formation. While fibroblasts and myofibroblasts, and to a minor degree endothelial and epithelial cells, produce the intestinal ECM, many more cell types are involved in ECM breakdown by releasing a broad spectrum of enzymes that can degrade essentially every ECM component, such as the various collagens, non-collagenous (glyco-) proteins, glycosaminoglycans, and proteoglycans. The most important of these enzymes are the matrix metalloproteinases (MMPs), a structurally related class of at least 20 zinc dependent proteases. ${ }^{45}$ MMPs are classified 
according to their primary specificities and structural features into interstitial collagenases (MMP-1, MMP-8, MMP13, MMP-18), gelatinases (degrading denatured and basement membrane collagens: MMP-2, MMP-9), stromelysins (degrading a broad spectrum of ECM substrates: MMP-3, MMP-7, MMP-10, MMP-11), elastases (MMP12 ), and membrane-type (transmembrane) MMPs (with broad substrate specificities: MMP-14, MMP-15, MMP16, MMP-17, MMP-24, MMP-25).

As uncontrolled MMP activity would virtually lead to dissolution of organs, MMP activity is strictly controlled, not only at the transcriptional and translational levels, but also by the requirement of proteolytic activation of the zymogens and by several protease inhibitors. Proteolytic activation occurs by the plasminogen activator-plasmin cascade and by certain active MMPs themselves, such as MMP-3, MMP-10, MMP14, and MMP-24. The most important physiological inhibitors are the tissue inhibitors of metalloproteinases (TIMP), mainly TIMP-1, which blocks almost all MMPs, and TIMP-2, which is specific for MMP-2. A fifth level of control is localisation of secreted MMPs either at cell membrane compartments that are involved in local ECM proteolysis (for example, by binding to ECM receptors that mediate cellular locomotion through the matrix ${ }^{67}$ ) or on certain ECM components, such as collagens. Interestingly, it is preferentially the inactive proforms of MMPs that bind to collagen which become released from the ECM on proteolytic activation. ${ }^{8}{ }^{9}$

This illustrates that both homeostasis and proteolytic remodelling of the ECM are highly sophisticated and tightly regulated processes, and that simply measuring upregulation or downregulation of MMPs and their inhibitors will give a very incomplete picture of ECM remodelling at best. In this line, no characteristic difference is found between procollagen mRNA levels as a measure of fibrogenesis ${ }^{2}$ and MMP and TIMP mRNA levels as a measure of fibrolysis $^{10-12}$ in inflamed colonic specimens from patients with CD and ulcerative colitis. This was initially unexpected as CD often leads to stenosis due to excess ECM deposition while fibrosis is uncommon in ulcerative colitis. But it comes as no surprise when one considers the complex regulation of fibrolysis in the transmural inflammation of CD.

The paper by Kirkegaard and colleagues $^{13}$ in this issue of Gut brings our understanding of the role of MMPs in CD a step further [see page 701]. Using complementary techniques, they identified and investigated MMP-3 and
MMP-9 as key players in fistulae of CD and other causes. At first glance the occurrence of fistulae, a manifestation of enhanced fibrolytic activity, in a fibrostenotic intestinal disease may appear paradoxical. However, severe inflammation which always leads to release and activation of MMPs by cells of the inflammatory infiltrate can drive both processes: fistulae will form when there is no rapid compensatory fibrogenic response to fill up the defect, perhaps favoured by a too quick reepithelialisation or re-endothelialisation; fibrosis will develop when the fibrogenic response is strong and quick, leading to scar formation. Both processes can obviously coexist in close proximity. What are the factors determining these divergent pathways? Recent studies demonstrated that at least early activation of MMPs is necessary to allow for a fibrogenic response, ${ }^{14}{ }^{15}$ either by destroying basement membranes which have a role in maintaining cellular quiescence and differentiation in the gut ${ }^{16}$ with subsequent mesenchymal activation, or by allowing mesenchymal cell migration and proliferation by removal of constraining ECM.

Thus the cellular source and temporospatial pattern of MMP release and activation probably explain these divergent pathologies. As mesenchymal cells (fibroblasts, myofibroblasts, and to a lesser extent endothelial cells) and inflammatory cells (mainly macrophages, monocytes, and neutrophils) are the major sources of MMPs and TIMPs, there must be a differently tuned interplay of these cells driving either fistula or fibrosis. Kirkegaard et al observed that acute fistulising inflammation in $\mathrm{CD}$ and other aetiologies is characterised by high expression of MMP-3 and MMP-9 coupled with high activity of MMP-2 and MMP-9 in inflammatory cells, while in chronic fistulae, MMP-9 almost disappeared but MMP-3 expression was maintained, with a shift to mesenchymal, mainly myofibroblastic, cells. ${ }^{13}$ The finding that TIMPs remained low in all fistula specimens is of interest as TIMP-1 in particular is a major determinant of fibrogenesis, as exemplified in liver fibrosis. ${ }^{17}$ Low expression of TIMP-1 is also characteristic of osteoarthritis, the hallmark of which is unopposed MMP activation in the joint leading to destruction of cartilage and bone, somewhat reminiscent of fistula formation in the gut. ${ }^{18}$ Also, it is osteoarthritis that has led to a novel concept of chronic fibrolytic inflammation that is driven by altered synovial fibroblasts, the equivalent of which could be myofibroblasts in chronic fistulising diseases. These fibro- blasts/myofibroblasts can secrete atypical chemokines attracting fibrolytic inflammatory cells on the one hand, and have a fibrolytic and migratory phenotype themselves on the other. ${ }^{19}$ MMP-3, which has a broad substrate specificity and which acts as a proactivator (in addition to plasmin), at least of MMP-1, MMP-2, and MMP-9, has been identified as a particularly aggressive enzyme in intestinal inflammation ${ }^{3}$ which favours invasiveness..$^{20}$ This does not exclude an important contribution by MMP-12, MMP-13, MMP-14, and MMP-19 which are expressed in inflamed intestine ${ }^{21}$ but were not considered in this study.

Can we derive therapeutic concepts from this and related studies on intestinal inflammation? A drug that effectively prevents emerging or eliminates chronic fistulae would be most welcome. Anti-inflammatory, antibiotic, and immunosuppressive approaches can lead to long term fistula control or even closure in $25-50 \%$ of patients, roughly doubling the placebo response which is unsatisfactory. ${ }^{1}$ Anti-tumour necrosis factor $\alpha($ TNF- $\alpha)$ strategies can lead to good short term and occasionally long term results in cases that are refractory to these therapies but treatment is costly and may have grave side effects. ${ }^{1}$ None the less, this approach is rational as TNF- $\alpha$ is a potent inducer of MMP-3 in intestinal myofibroblasts. ${ }^{3}$

Based on this and other studies, four novel strategies aimed at inhibiting intestinal inflammation and remodelling in inflammatory bowel disease in general, or in fistulising CD in particular, merit further exploration. These are the use of: (1) inhibitors of growth factors or cytokines, such as epidermal growth factor, hepatocyte growth factor, insulin-like growth factor (IGF-I and IGF-II), fibroblast growth factor (aFGF, bFGF), interleukin 1 , and stem cell factor that induce MMPs in epithelial and mesenchymal cells ${ }^{22}$; (2) synthetic inhibitors of kinases that trigger MMP production, especially p38 kinase ${ }^{23}$; (3) synthetic MMP inhibitors that were shown to ameliorate experimental colitis in mice ${ }^{24}$; and (4) inhibitors of integrins (that is, cellular receptors for ECM proteins that can bind to and/or induce certain MMPs). ${ }^{65-28}$ Inhibition of growth factors/cytokines and kinases always carries the risk of side effects because of their importance in normal tissue regeneration and of their ubiquitous expression in other cells and organs. Inhibition of MMPs appears more promising, especially as the first generation of broad spectrum inhibitors which have multiple side effects are becoming replaced by orally available subtype specific agents. ${ }^{18}$ However, the 
necessity for cell-type specific targeting (for example, to MMP-3 expressing myofibroblasts of fistulae) remains an unsolved problem. Therefore, it is attractive to target integrins that promote MMP-expression as many of these receptors are cell-type specific. Thus MMP-1, MMP-2, and MMP-3, MMP14, MMP-1 and MMP-3, and MMP-9 are induced and activated by integrins $\alpha 2 \beta 1, \alpha 4 \beta 1, \alpha 6 \beta 1$, and $\alpha v \beta 3$, respectively, which are predominantly found on activated (myo-) fibroblasts. ${ }^{625-28}$ Such inhibitors have (in part) been developed, and orally available agents are in phase I and II clinical studies (for example, for metastatic tumour disease). ${ }^{29}$ It remains to combine the most promising of these agents, alone or in combination, with established therapies in preclinical and clinical studies, for our patients with complicated inflammatory bowel disease.

\section{ACKNOWLEDGEMENTS}

$\mathrm{T}$ Freitag was supported by the ELAN Fonds of the University of Erlangen-Nuernberg.

Gut 2004;53:622-624.

doi: 10.1136/gut.2003.034207

\section{Authors' affiliations}

D Schuppan, T Freitag, Department of Medicine I, University of Erlangen-Nürnberg, Germany

Correspondence to: Professor

D SchuppanDepartment of Medicine I,

University of Erlangen-Nürnberg, Ulmenweg

18, 91054 Erlangen, Germany; detlef.

schuppan@medl.imed.uni-erlangen.de

\section{REFERENCES}

1 Sandborn WJ, Fazio WW, Feagan BG, et al. AGA technical review on perianal Crohn's disease. Gastroenterology 2003;125:1508-30.
2 Matthes $\mathrm{H}$, Herbst $\mathrm{H}$, Schuppan D, et al. Cellular localization of procollagen gene transcripts in inflammatory bowel dieseases. Gastroenterology 1992; 102:431-42.

3 Pender SL, Tickle SP, Docherty AJ, et al. A major role for matrix metalloproteinases in T cell injury in the gut. J Immunol 1997; 158:1582-90.

4 Brinckerhoff CE, Matrisian LM. Matrix metalloproteinases: a tail of a frog that became a prince. Nat Rev Mol Cell Biol 2002;3:207-14.

5 Nagase H, Woessner JF. Matrix metalloproteinases. J Biol Chem 1999:274:21491-4.

6 Dumin JA, Dickeson SK, Stricker TP. Procollagenase-1 (matrix metalloproteinase-1) binds the alpha(2)beta(1) integrin upon release from keratinocytes migrating on type I collagen. J Biol Chem $2001 ; 276: 29368-74$.

7 Yu Q Stamenkovic I. Localization of matrix metalloproteinase 9 to the cell surface provides a mechanism for CD44-mediated tumor invasion. Genes Dev 1999; 13:35-48.

8 Schuppan D, Ruehl M, Somasundaram R, et al Matrix as a modulator of hepatic fibrogenesis. Semin Liver Dis 2001;21:351-72.

9 Ruehl M, Somasundaram R, Farndale R, et al. Pro-matrix-metalloproteinase-2 (MMP-2) is bound to liver collagens via collagenous consensus mitives and released from extracellular matrix stores by activation. (abstract). Gastroenterology 2002;122(suppl 1):A653.

10 Günther U, Schuppan D, Matthes H, et al. Fibrogenesis and fibrolysis in collagenous colitis: patterns of procollagen type I and IV, matrixmetalloproteinase-1, and TIMP-1 gene expression. Am J Pathol, 155:493-503.

11 Heuschkel RB, MacDonald T, Monteleone G et al. Imbalance of stromelysin-1 and TIMP-1 in the mucosal lesions of children with inflammatory bowel disease. Gut 2000;47:57-62.

12 von Lampe B, Barthel B, Coupland SE, et al. Differential expression of matrix metalloproteinases and their tissue inhibitors in colon mucosa of patients with inflammatory bowel disease. Gut 2000:47:63-73.

13 Kirkegaard T, Hansen A, Bruun E, et al. Expression and localisation of matrix metalloproteinases and their natural inhibitors in fistulae of patients with Crohn's disease. Gut 2004:53:701-9.

14 Swiderski RE, Dencoff JE, Floerchinger CS, et al. Differential expression of extracellular matrix remodeling genes in a murine model of bleomycin-induced pulmonary fibrosis. Am J Pathol 1998; 152:821-8.

15 Ammarguellat FZ, Gannon PO, Amiri F, et al. Fibrosis, matrix metalloproteinases, and inflammation in the heart of DOCA-salt hypertensive rats: role of ET(A) receptors. Hypertension 2002;39:679-84.
16 Fritsch C, Simon-Assmann P, Kedinger M, et al. Cytokines modulate fibroblast phenotype and epithelial-stroma interactions in rat intestine. Gastroenterology 1997;112:826-38.

17 Benyon RC, Arthur MJ. Extracellular matrix degradation and the role of hepatic stellate cells. Semin Liver Dis 2001;21:373-84.

18 Baker AH, Edwards DR, Murphy G. Metalloproteinase inhibitors: biological actions and therapeutic opportunities. J Cell Sci 2002; 115:3719-27.

19 Buckley CD. Why does chronic inflammatory joint disease persist? Clin Med 2003;3:361-6

20 Mercapide J, Lopez De Cicco R, Castresana JS et al. Stromelysin-1/matrix metalloproteinase-3 (MMP-3) expression accounts for invasive properties of human astrocytoma cell lines. Int J Cancer 2003;106:676-82.

21 Salmela MT, MacDonald T, Black D, et al. Upregulation of matrix metalloproteinases in a model of T cell mediated tissue injury in the gut: analysis by gene array and in situ hybridisation. Gut 2002;51:540-7.

22 Liu Z, Klominek J. Regulation of matrix metalloprotease activity in malignant mesothelioma cell lines by growth factors. Thorax 2003;58:198-203.

23 Lee HS, Miau LH, Chen $\mathrm{CH}$, et al. Differential role of p38 in IL-1alpha induction of MMP-9 and MMP-13 in an established liver myofibroblast cell line. J Biomed Sci 2003;10:757-65.

24 Di Sebastiano P, di Mola FF, Artese L, et al. Beneficial effects of Batimastat (BB-94), a matrix metalloproteinase inhibitor, in rat experimental colitis. Digestion $2001 ; 63: 234-9$

25 Laver-Fields JL, Sritharan T, Stack MS, et al. Selective hydrolysis of triple-helical substrates by matrix metalloproteinase-2 and -9. J Biol Chem 2003;278:18140-5.

26 Pender SL, Salmela MT, Monteleone G, et al. Ligation of alpha4 $\beta 1$ integrin on human intestinal mucosal mesenchymal cells selectively up-regulates membrane type- 1 matrix metalloproteinase and confers a migratory phenotype. Am J Pathol 2000:157:1955-62.

27 Chen CC, Chen N, Lau LF. The angiogenic factors Cyr61 and connective tissue growth factor induce adhesive signaling in primary human skin fibroblasts. J Biol Chem 2001;276: 10443-52.

28 Rolli M, Fransvea E, Pilch J, et al. Activated integrin alphavbeta3 cooperates with metalloproteinase MMP-9 in regulating migration of metastatic breast cancer cells. Proc Natl Acad Sci U S A 2003;100:9482-7

29 Tucker GC. Alpha $v$ integrin inhibitors and cancer therapy. Curr Opin Invest Drugs 2003:4:722-31.

\section{Hepcidin: what every gastroenterologist should know}

\section{A P Walker, J Partridge, S K Srai, J S Dooley}

The circulating peptide hepcidin is important in the normal response to iron overload, the pathogenesis of haemochromatosis, and possibly the anaemia of chronic disease

n health, the body content of iron is maintained within fairly narrow limits to provide sufficient iron for synthesis of ferroproteins essential for oxygen transport and catalysis yet avoid the toxic effects of excess. Early experiments provided tantalising evidence for a humoral regulatory factor. Serum obtained from iron repleted rats inhibited iron absorption in normal rat duodenum. ${ }^{1}$ For many years this putative factor remained elusive. However, recent studies indicate that a peptide hormone, hepcidin, may play a crucial regulatory role in normal iron homeostasis, haemochromatosis, and the anaemia of chronic disease. ${ }^{2}$

Hepcidin was identified not from studies of iron homeostasis but from investigation of novel antimicrobial peptides in body fluids. Krause and colleagues ${ }^{3}$ screened human blood ultrafiltrate (a source of the antimicrobial peptides defensins) for small cysteine rich peptides. A 25 amino acid peptide with a mass of $2.7 \mathrm{kDa}$ was found, containing a remarkable eight disulphide bonded cysteine residues. It showed antimicrobial activity against some bacteria and the yeast Saccharomyces cerevisiae. Quantitative reverse 
transcription-polymerase chain reaction showed predominant expression in liver. The peptide was called LEAP-1 (liver-expressed antimicrobial peptide). ${ }^{3}$ The cDNA sequence predicted an 84 amino acid pre-propeptide with two cleavage sites. The first predicts cleavage of the $\mathrm{N}$ terminal endoplasmic reticulum targeting signal sequence (amino acids 1-24). The second consensus cleavage site for prohormone convertases would yield the central prodomain (amino acids 25-59) plus the 25 amino acid C terminal peptide (also called hepcidin-25; amino acids 60-84). A slightly truncated 20 amino acid peptide was also found (hepcidin 20; amino acids 65-84). Independently, Park and colleagues $^{4}$ isolated the same cysteine rich peptide from human urine and named it hepcidin, reflecting its hepatic expression and bactericidal properties. In addition to hepcidin-20 and hepcidin-25, a minor 22 amino acid form was found (hepcidin-22; amino acids 63$84)$. The antimicrobial activity of urinary hepcidin was inhibited by $100-150 \mathrm{mM}$ $\mathrm{NaCl},{ }^{4}$ similar to the normal range for plasma sodium ( 135-145 mM). Whether circulating plasma hepcidin plays a significant antimicrobial role in vivo therefore remains unclear.

Experiments in mice have shown that hepcidin plays a role in iron regulation. Pigeon et al identified mouse liver hepcidin mRNA because it was induced by carbonyl iron overload. ${ }^{5}$ The mouse has two hepcidin genes in tandem (probably arising from a duplication event), located adjacent to the upstream stimulatory factor 2 (Usf2) transcription factor gene. ${ }^{5}$ Mice that lack hepatic hepcidin expression, due to targeted disruption of the adjacent Usf2 gene, developed predominant iron loading of parenchymal cells of the liver and pancreas with relative sparing of the macrophage rich spleen. ${ }^{6}$ Similar patterns of iron overload in $\mathrm{Hfe}$ knockout and Usf2 (hepcidin deficient) knockout mice suggested that hepcidin and $\mathrm{Hfe}$ may function in the same regulatory pathway. Hepcidin was proposed to be a negative regulator (that is, "inhibitor") of iron absorption in the duodenum and of iron release from macrophages. ${ }^{6}$ This was supported by demonstration that transgenic mice constitutively expressing liver hepcidin died within a few hours of birth with decreased body iron levels and severe microcytic hypochromic anaemia.?

Further observations implicate hepcidin in the anaemia of chronic disease. This is the most common anaemia of hospitalised patients, often associated with infection, cancer, and autoimmune diseases. There is a diminished response of erythroid precursors to erythropoietin, decreased survival of erythrocytes, impaired iron absorption, and retention of iron in macrophages. The net effect would be to decrease the iron available to erythroid precursor cells. ${ }^{89}$ Two patients with severe iron refractory anaemia associated with hepatic adenoma showed spontaneous resolution of anaemia after removal of the tumour.' The adenomatous tissue expressed inappropriately high levels of hepcidin mRNA. On the basis of these observations, it was proposed that hepcidin may be important in the pathogenesis of anaemia of chronic disease. Analysis of urinary hepcidin excretion in patients with anaemia due to chronic infection or severe inflammatory disease provided some confirmatory evidence of increased hepcidin levels in response to inflammation in humans. ${ }^{10}$ In these patients, hepcidin excretion correlated with serum ferritin concentration which, like hepcidin, increases in response to both elevated body iron stores and inflammation. Interestingly, injection of erythropoietin into mice was shown to decrease dramatically liver hepcidin expression. Therefore, the efficacy of erythropoietin in non-renal anaemias such as cancer and autoimmune diseases may result from both stimulation of erythropoiesis and inhibition of hepcidin expression, leading to increased plasma iron levels. ${ }^{11}$

Regulation of hepcidin expression has been investigated in cultured cells. Surprisingly, iron loading of primary human hepatocytes with either ferric ammonium citrate or diferric transferrin decreased hepcidin mRNA levels. ${ }^{10}$ This is in contrast with experiments in mice in which dietary or parenteral iron loading increased hepcidin mRNA levels. ${ }^{5}$ This suggested that during iron overload in the whole animal, a signal from non-parenchymal cells may induce hepatocytes to express hepcidin. ${ }^{10}$ Mouse liver hepcidin mRNA is induced not only by iron overload but also by treatment with bacterial lipopolysaccharide, hinting that iron and inflammatory cytokines may have a common signalling pathway. ${ }^{5}$ Hepcidin mRNA in primary human hepatocytes was induced either by medium conditioned by monocytes exposed to lipopolysaccharide or by interleukin 6 (IL-6). ${ }^{10} \mathrm{At}$ the level of regulation by transcription factors, the promoters of human and mouse hepcidin genes contain at least one functional binding site for CCAAT/ enhancer binding protein $\alpha(\mathrm{C} / \mathrm{EBP} \alpha)$, a transcription factor highly expressed in adult liver which appears to stimulate hepcidin expression. Hepatocyte nuclear factor $4 \alpha(\mathrm{HNF} 4 \alpha)$ appears to reduce hepcidin expression. ${ }^{12}$
The medical importance of hepcidin is emphasised by recent studies in human iron overload. Homozygous mutations of hepcidin have been demonstrated in two families with juvenile haemochromatosis. ${ }^{13}$ This disorder is characterised by a rapid rate of iron loading, usually causing presentation before the age of 30 years. There is a high frequency of endocrine and cardiac iron overload, and failure of early diagnosis and treatment may be fatal. ${ }^{14}$ Juvenile haemochromatosis is genetically heterogeneous with a second form mapping to chromosome 1q21. Whether this second gene will encode another protein in the hepcidin-HFE pathway remains to be resolved. ${ }^{15}$ The potential interaction between hepcidin and HFE has also been suggested by the description of haemochromatosis associated with one mutated allele of both hepcidin and $H F E$, termed "digenic inheritance". ${ }^{16}$

The classical HFE related form of the disease accounts for more than $90 \%$ of well characterised haemochromatosis patients in the UK. ${ }^{17}$ In HFE related haemochromatosis and in Hfe knockout mice, there is failure to upregulate hepcidin levels despite hepatic iron overload. This indicates that the HFE protein is involved in regulation of hepcidin levels in response to iron. Disruption of the normal hepcidin response to body iron stores may contribute to the pathogenesis of iron overload seen in HFE related haemochromatosis. ${ }^{18-20}$

Recognition of liver produced hepcidin as an iron regulatory factor has challenged the hypothesis that the control of iron absorption in relation to body stores is mediated in duodenal crypts. Hepcidin has revived the concept that some regulation may be mediated by the liver. Rats switched from a control to an iron deficient diet showed changes in hepcidin expression in close temporal relationship with changes in duodenal iron transporter expression. This suggested that hepcidin may act directly on villus enterocytes, pointing to the liver as a regulatory site. ${ }^{21}$ Certainly, siderosis in Kupffer cells, often on a background of mild iron deposition in hepatocytes, is a familiar feature of common liver diseases such as hepatitis $C$ infection and alcoholic liver disease. ${ }^{22}$ Whether increased concentration of hepcidin, perhaps in response to inflammation, has a role in the hepatic siderosis observed in viral and alcoholic liver disease remains to be demonstrated.

To date, investigation of hepcidin in various clinical conditions has been impeded by the lack of anti-hepcidin antibodies and suitable assays. Recently, a western blot densitometric assay was reported using an antibody raised 
against hepcidin-25, allowing quantitation of human hepcidin in serum samples. ${ }^{23}$ In this issue of Gut, Kulaksiz and colleagues ${ }^{24}$ describe antisera raised against two unique synthetic peptides corresponding to the predicted human hepcidin prodomain (two antisera to the same peptide) and the mature hepcidin C terminal peptide [see page 735 ]. All three antisera detected immunoreactive bands estimated at 10 and $20 \mathrm{kDa}$ on western blots of guinea pig and human liver and HepG2 cells. The $10 \mathrm{kDa}$ band only was detected faintly in human serum. Immunohistochemistry of guinea pig and human liver with all three antisera showed staining in hepatocytes with a basolateral expression pattern. This confirms and extends earlier mRNA results, and is consistent with basolateral release of hepcidin into the liver sinusoids. ${ }^{24}$

A new enzyme linked immunosorbent assay (ELISA) was developed using the prodomain antiserum. The ELISA was used to investigate serum levels of prohepcidin immunoreactivity in controls and patients with haemochromatosis, renal anaemia, and chronic renal insufficiency. The mean level of pro-hepcidin immunoreactivity detected in the serum of healthy volunteers was an order of magnitude greater than levels of hepcidin detected in human urine. ${ }^{4}$ Prohepcidin immunoreactivity was increased in chronic renal insufficiency patients who had normal haemoglobin levels compared with the healthy control group, despite erythropoietin treatment, which has been observed to decrease hepatic hepcidin expression. ${ }^{11}$ These observations are therefore consistent with renal metabolism and/or elimination of peptide. Pro-hepcidin was decreased in HFE related haemochromatosis patients (C282Y homozygous) compared with healthy controls, ${ }^{24}$ consistent with earlier mRNA studies, ${ }^{18}$ and indicating defective hepcidin regulation in HFE related haemochromatosis.

Questions and inconsistencies remain regarding the size and identity of hepcidin immunoreactive bands on western blots. The sequence of hepcidin-25 predicts a mass of $2.7 \mathrm{kDa}$, corresponding to the result determined by mass spectrometry. ${ }^{3}$ Furthermore, the oxidised synthetic hepcidin-25 co-migrates with native hepcidin-25 in analytical high pressure liquid chromatography and capillary electrophoresis. ${ }^{25}$ On western blots however, serum hepcidin-25 immunoreactivity has been detected with an apparent mass of $10 \mathrm{kDa}$, comigrating with the synthetic peptide, ${ }^{23}$ possibly reflecting aggregation of hepcidin monomers. ${ }^{26}$ Kulaksiz et al detected bands of $10 \mathrm{kDa}$ and $20 \mathrm{kDa}$ with their three antisera on western blots. ${ }^{24}$ They attributed the $10 \mathrm{kDa}$ band to prohepcidin on the grounds that it was detected by antisera to both the mature hepcidin peptide and to the prodomain. However, the predicted mass of pro-hepcidin is $6.9 \mathrm{kDa}$; that of pre-pro-hepcidin is $9.4 \mathrm{kDa}$ (ExPASy programme: http://ca.expasy.org/tools/ peptide-mass.html). ${ }^{27}$ It might be informative to compare the mobility of synthetic peptides versus the bands observed in human serum in this system. $^{24}$ Perhaps attention to denaturation conditions and accurate verification of experimentally determined molecular masses may help to clarify the discrepancies.

Is pro-hepcidin an active player in iron regulation or merely a precursor and an indirect measure of hepcidin potential? Interestingly, a homozygous point mutation of the human hepcidin prodomain has been detected, predicting a threonine to methionine substitution at amino acid 31 (T31M). This individual had normal serum iron indices, normal haemoglobin, and normal mean corpuscular volume. ${ }^{28}$ However, this residue is not conserved in evolution: both wild-type mouse hepcidin genes have a methionine at the position equivalent to human threonine 31 . The normal phenotype associated with homozygous T31M mutation therefore does not resolve the role of pro-hepcidin.

In summary, hepcidin is a peptide hormone with important biological effects on iron metabolism. It has sequence homology to antimicrobial peptides, although whether this function is conserved in vivo remains to be demonstrated. Hepcidin is derived by cleavage of a pre-propeptide; questions remain about the processing and activity of the peptide products. It has been implicated as a regulator of body iron stores and mutations have been found in some families with juvenile haemochromatosis. Iron balance is probably sensed by Kupffer cells and signalled to hepatocytes by cytokines such as IL-6. Hepcidin expression is also induced by inflammatory agents giving it a potential role in the anaemia of chronic disease. The reagents and assays described ${ }^{24}$ will permit investigations of the role of hepcidin in clinical samples in relation to the siderosis observed in viral and alcoholic liver diseases. This peptide is a fascinating addition to the family of molecules involved in iron metabolism. Future studies of its action and regulation in vivo and in vitro should fill in some of the tantalising gaps in our understanding of this increasingly complex field.

\section{ACKNOWLEDGMENTS}

Research in the authors' laboratories is supported by European Commission Grant QLK6-CT-1999-02237, Wellcome Trust Grant 059762/Z/99/Z, and BBSRC Project Grant 90/ D1340.

Gut 2004;53:624-627. doi: $10.1136 /$ gut.2003.030304

\section{Authors' affiliations}

\section{A P Walker, J Partridge, J S Dooley, Centre} for Hepatology, Department of Medicine, Royal Free and University College Medical School, University College London, London, UK

S K Srai, Department of Biochemistry and Molecular Biology, Royal Free and University College Medical School, University College London, London, UK

Correspondence to: Dr A P Walker, Centre for Hepatology, Department of Medicine, Royal Free and University College Medical School (UCL), Royal Free Campus, Rowland Hill St, London NW3 2PF, UK; a.walker@rfc.ucl.ac.uk

\section{REFERENCES}

1 MacDermott RP, Greenberger NJ. Evidence for a humoral factor influencing iron absorption. Gastroenterology 1969;57:117-25.

2 Ganz T. Hepcidin, a key regulator of iron metabolism and mediator of anemia of inflammation. Blood 2003;102:783-8.

3 Krause A, Neitz S, Magert HJ, et al. LEAP-1, a novel highly disulfide-bonded peptide, exhibits antimicrobial activity. FEBS Lett 2000;480: 147-50.

4 Park $\mathrm{CH}$, Valore EV, Waring $\mathrm{AJ}$, et al. Hepcidin, a urinary antimicrobial peptide synthesised in the liver. J Biol Chem 2001;276:7806-10.

5 Pigeon C, llyin G, Courselaud B, et al. A new mouse liver-specific gene, encoding a protein homologous to human antimicrobial peptide hepcidin, is overexpressed during iron overload. $J$ Biol Chem 2001;276:7811-19.

6 Nicolas G, Bennoun M, Devaux I, et al. Lack of hepcidin gene expression and severe tissue iron overload in upstream stimulatory factor 2 (USF2) knockout mice. Proc Natl Acad Sci USA $2001 ; 98: 8780-5$.

7 Nicolas G, Bennoun M, Porteu A, et al. Severe iron deficiency anemia in transgenic mice expressing liver hepcidin. Proc Natl Acad Sci USA 2002;99:4596-601.

8 Weiss G. Pathogenesis and treatment of anaemia of chronic disease. Blood Rev 2002;16:87-96.

9 Weinstein DA, Roy CN, Fleming MD, et al. Inappropriate expression of hepcidin is associated with iron refractory anemia: implications for the anemia of chronic disease. Blood 2002;100:3776-81.

10 Nemeth E, Valore EV, Territo M, et al. Hepcidin, a putative mediator of anemia of inflammation, is a type II acute-phase protein. Blood 2003;101:2461-3.

11 Nicolas G, Viatte L, Bennoun M, et al. Hepcidin, a new iron regulatory peptide. Blood Cells Mol Dis 2002;29:327-35.

12 Courselaud B, Pigeon C, Inoue Y, et al. C/EBP alpha regulates hepatic transcription of hepcidin, an antimicrobial peptide and regulator of iron metabolism. Cross-talk between C/EBP pathway and iron metabolism. J Biol Chem 2002;277:41163-70.

13 Roetto A, Papanikolaou G, Politou M, et al. Mutant antimicrobial peptide hepcidin is associated with severe juvenile hemochromatosis. Nat Genet 2003;33:21-2.

14 Kelly AL, Rhodes DA, Roland JM, et al. Hereditary juvenile haemochromatosis: a genetically heterogeneous life-threatening ironstorage disease. QJM 1998;91:607-18. 
15 Roetto A, Totaro A Cazzola M, et al. Juvenile hemochromatosis locus maps to chromosome lq. Am J Hum Genet 1999;64:1388-93.

16 Merryweather-Clarke AT, Cadet E, Bomford A, et al. Digenic inheritance of mutations in HAMP and HFE results in different types of haemochromatosis. Hum Mol Genet 2003; 12:2241-7.

17 The UK Haemochromatosis Consortium A simple genetic test identifies $90 \%$ of UK patients with haemochromatosis. Gut 1997;41:841-4.

18 Bridle KR, Frazer DM, Wilkins SJ, et al. Disrupted hepcidin regulation in HFE-associated haemochromatosis and the liver as a regulator of body iron homoeostasis. Lancet 2003:361:669-73.

19 Ahmad KA, Ahmann JR, Migas MC, et al Decreased liver hepcidin expression in the Hfe knockout mouse. Blood Cells Mol Dis 2002;29:361-6.
20 Muckenthaler M, Roy CN, Custodio AO, et al. Regulatory defects in liver and intestine implicate abnormal hepcidin and Cybrdl expression in mouse hemochromatosis. Nat Genet 2003;34:102-7.

21 Frazer DM, Wilkins SJ, Becker EM, et al. Hepcidin expression inversely correlates with the expression of duodenal iron transporters and iron absorption in rats. Gastroenterology 2002;123:835-44.

22 Turlin B, Deugnier Y. Evaluation and interpretation of iron in the liver. Semin Diagn Pathol 1998;15:237-45.

23 Dallalio G, Fleury T, Means RT. Serum hepcidin in clinical specimens. Br J Haematol 2003; 122:996-1000.

24 Kulaksiz H, Gehrke SG, Janetzko A, et al. Prohepcidin: expression and cell specific localisation in the liver and its regulation in hereditary haemochromatosis, chronic renal insufficiency, and renal anaemia. Gut 2003:53:735-43.
25 Kluver E, Schulz A, Forssmann WG, et al. Chemical synthesis of beta-defensins and LEAP-1/hepcidin. J Peptide Res 2002;59:241-8

26 Hunter HN, Fulton DB, Ganz T, et al. The solution structure of human hepcidin, a peptide hormone with antimicrobial activity that is involved in iron uptake and hereditary hemochromatosis. J Biol Chem 2002;277:37597-603.

27 Wilkins MR, Lindskog I, Gasteiger, E, et al. Detailed peptide characterisation using PEPTIDEMASS - a World-Wide Web accessible tool. Electrophoresis 1997; 18:403-8.

28 Lee P, Gelbart T, West C, et al. A study of genes that may modulate the expression of hereditary hemochromatosis: transferrin receptor- 1 , ferroportin, ceruloplasmin, ferritin light and heavy chains, iron regulatory proteins (IRP)- 1 and -2 , and hepcidin. Blood Cells Mol Dis 2001;27:783-802.

\section{Bringing science to the art of diagnosis P Moayyedi}

\section{Which gastrointestinal symptoms are useful in distinguishing organic from functional disease?}

$\mathrm{P}$ atients and clinicians are becoming increasingly intolerant of diagnostic uncertainty. This is reflected in the rising demand for endoscopic procedures $^{1}$ implicitly suggesting that gastrointestinal symptoms are an unreliable indicator of serious pathology. Unfortunately, the growing array of tests that are being demanded for patients are placing further pressures on already stretched health care budgets. The natural reaction to this is to evaluate whether we can improve on the value of the history to diagnose gastrointestinal disease. This process was started over 30 years ago when researchers such as Card and colleagues $^{23}$ and de Dombal and colleagues ${ }^{4} 5$ evaluated the use of computers to aid the clinician in making diagnoses in patients with upper gastrointestinal symptoms. The enthusiasm for this approach faded when data suggested that computer improved diagnostic accuracy of computers was not sufficient to prevent investigations. ${ }^{6}$ The paucity of subsequent research in this field is disappointing as it would be useful to know what information computers were using that enhanced diagnostic acumen. The article by Hammer and colleagues ${ }^{7}$ in this issue of Gut [see page 666] is therefore refreshing as it prospectively evaluates a wide range of gastrointestinal symptoms to establish which are useful in distinguishing organic from functional disease. The strength of this study is that it evaluates a large relatively unselected group of patients, reducing spectrum and selection bias. ${ }^{8}$ It also divided patients into those with and without organic disease rather than subdividing the data into different diagnoses. This improves the power of the study and gives the clinician overall information on whether the patient is likely to have an organic disease.

Their data suggest that aspects of the history are valuable diagnostic tools for lower gastrointestinal disease. They identify three "alarm features" that were important independent predictors of organic lower gastrointestinal pathology. These were age over 50 years, male sex, and blood on the toilet paper. They also identified five "non-alarm" features (frequent abdominal pain, radiating pain, pain with loose bowel movements, reflux, and absence of diarrhoea) that independently predicted functional bowel disease. The approach of positively diagnosing functional bowel disease with non-alarm symptoms or positively diagnosing organic disease with alarm symptoms performed equally well. The interesting observation is that putting these two pieces of information together improved the accuracy of the model. This is intuitive, as a clinician is likely to weigh up the absence of alarm symptoms and the presence of positive features indicating a functional bowel disorder before deciding that the patient is at low risk of significant organic disease.

These data will provide useful information for the Rome group ${ }^{9}$ when they next consider guidelines for the assessment of irritable bowel syndrome (IBS). They have highlighted symptoms similar to the classical Manning criteria that are important in making a positive diagnosis of functional gastrointestinal disease but also other characteristics such as radiating and frequent pain that make IBS more likely. Unfortunately, the model is probably not sufficiently accurate to be used to exclude patients from investigation in clinical practice. Using the prevalence of lower gastrointestinal organic disease in the article, the model had a positive predictive value of $79 \%$ and a negative predictive value of $86 \%$. The possibility of missing organic pathology in $14 \%$ of patients would lead most clinicians to opt for investigating even if the model predicted a low probability of disease. The accuracy of the model may have been improved if non-gastrointestinal symptoms such as backache and frequency of micturition had been included ${ }^{10}$ but the concern about using models to predict organic disease is emphasised by the conflicting messages from other studies. For example, three papers also found that rectal bleeding ${ }^{1-13}$ predicted organic disease whereas two studies ${ }^{14}{ }^{15}$ found no statistically significant association. Hammer et al found that weight loss and anorexia were not independent predictors of disease whereas others ${ }^{13} 1516$ reported these symptoms were associated with organic pathology. Finally, Hammer and colleagues ${ }^{7}$ found that severe abdominal pain was associated with a reduced risk of having organic pathology in the univariate analysis. This observation is supported by one study $^{12}$ whereas another suggested 
abdominal pain is associated with colorectal disease. ${ }^{17}$

These inconsistent findings probably relate to differences in the design and populations of the different studies. The quality of the data collection on gastrointestinal symptoms, sample size, and prevalence of underlying organic disease varied between studies. In particular, Hammer et al had very few colorectal cancers in their sample and the main organic disease driving the model was inflammatory bowel disease. If ulcerative colitis was the main disease found, then rectal bleeding and absence of pain will predict pathology and weight loss may not be an important feature in the model. It is interesting that the study ${ }^{12}$ that also had few colorectal cancers found similar results, whereas the report $t^{17}$ that evaluated a larger number of colorectal cancers found that features such as weight loss and abdominal pain were important. The case mix of disease in the underlying population is likely to have a large influence on the symptoms that computers models will predict are important.

Upper gastrointestinal symptoms are a good example of this. Hammer et al found that weight loss, dysphagia, age, and sex were not predictors of organic pathology whereas other researchers have found these to be significantly associated with the risk of upper gastrointestinal cancer. ${ }^{18} 19$ Indeed, it is almost inconceivable that male sex and increasing age would not be risk factors for upper gastrointestinal malignancy given what is known about the epidemiology of these cancers. ${ }^{1}$ Hammer et al did not find that these were important because the majority of their patients had gastro-oesophageal reflux and peptic ulcer and these diseases were driving the model. It is not surprising therefore that heartburn symptoms and aspirin use were found to predict pathology whereas alarm symptoms did not.

Although alarm symptoms may be of more value than is suggested by this paper, the overall message is consistent with other researchers. Factors that are found to be predictive of functional or organic disease are not very useful clinically. The model used by Hammer et al found it very difficult to distinguish between groups and as most patients had organic disease it generally defaulted to assigning patients to the disease group. Others have found the same problem: individual factors may be statistically significantly associated with disease but when they are combined in a model they generally perform very poorly. ${ }^{20}$ This is particularly true when the models are tested prospectively $y^{21}$ or transferred from a hospital to a primary care setting. ${ }^{22}$

Science has a great deal to offer the clinician in helping determine a diagnosis from the patient history. Statistical techniques can identify symptoms and signs that are important to consider and those that do not contribute to making a diagnosis. The problem is that a single study is not sufficient. After all, we do not rely on one study to definitively tell us that smoking causes lung cancer or Helicobacter pylori causes distal gastric adenocarcinoma. There is a need for a range of diagnostic studies conducted in different settings using different designs. The common feature of all should be the careful prospective collection of a detailed symptom assessment. ${ }^{23}$ When sufficient data have been accumulated, a picture will emerge on what are the important features that identify a patients as having organic disease. The problem that is addressed also has to be amenable to this approach. It will be difficult to use the history to guide us in patients with upper gastrointestinal disease but the situation with lower gastrointestinal pathology looks more promising. Insights provided by diagnostic studies may allow us to avoid invasive tests in some patients and identify others as having a high risk of serious colorectal disease that warrants urgent investigation. It is not sufficient to show the sensitivity and specificity of this approach as the ultimate goal is to provide more cost effective health care to patients. ${ }^{24}$ Randomised controlled trials will therefore be required to assess whether a more thorough clinical history will reduce costs or improve patient outcomes.

Gut 2004;53:627-628.

doi: 10.1136/gut.2003.032219

Correspondence to: Professor P Moayyedi, Gastroenterology Division, McMaster University-HSC 4W8, 1200 Main St West, Hamilton, Ontario, Canada L8N 3Z5; evans|@ mcmaster.ca

\section{REFERENCES}

1 Delaney BC, Moayyedi P. Dyspepsia. Health care needs assessment, 3rd series. Department of Health, Radcliffe Medical Press, 2003 (http:// hcna.radcliffe-oxford.com/dysframe.htm)
2 Card WI, Good IJ. Logical foundations of medicine. BMJ 1971;i:718-20.

3 Lucas RW, Card WI, Knill-Jones RP, et al. Computer interrogation of patients. BMJ 1976;ii:623-5.

4 Horrocks JC, McCann AP, Staniland JR, et al. Computer-aided diagnosis: description of an adaptable system, and operational experience with 2,034 cases. BMJ 1972;ii:5-9.

5 Horrocks JC, de Dombal FT. Computer-aided diagnosis of "dyspepsia". Am J Dig Dis 1975;20:397-406.

6 Horrocks JC, de Dombal FT. Diagnosis of dyspepsia from data collected by a physician's assistant. BMJ 1975; ;ii:421-3.

7 Hammer J, Eslick GD, Howell SC, et al. Diagnostic yield of alarm features in irritable bowel syndrome and functional dyspepsia. Gut 2003;53:666-72.

8 Moayyedi P, Duffy J, Delaney B. New approaches to enhance the accuracy of the diagnosis of reflux disease. Gut 2003;53(suppl iv): 55-57.

9 Talley NJ, Stanghellini V, Heading RC, et al. Functional gastrointestinal disorders. Gut 1999:45(suppl ii):ii37-42.

10 Maxion DG, Morris J, Whorwell PJ. More accurate diagnosis of irritable bowel syndrome by the use of "non-colonic" symptomatology. Gut 1991:32:784-6.

11 Goulston KJ, Cook I, Dent OF. How important is rectal bleeding in the diagnosis of bowel cancer and polyps? Lancet 1986;ii:261-4.

12 Fijten GH, Starmans R, Muris JWM et al. Predictive value of signs and symptoms for colorectal cancer in patients with rectal bleeding in general practice. Fam Pract 1995;12:279-86.

13 Majumdar SR, Fletcher RH, Evans AT. How does colorectal cancer present? Symptoms, duration, and clues to location. Am J Gastroenterol 1999; $94: 3039-45$

14 Helfand M, Marton KI, Zimmer-Gembeck MJ, et al. History of visible rectal bleeding in a primary care population. JAMA 1997;277:44-8.

15 Chak A, Post AB, Cooper GS. Clinical variables associated with colorectal cancer on colonoscopy: a prediction model. Am J Gastroenterol 1996:91:2483-8.

16 Zarchy TM, Ershoff D. Which clinical variables predict an abnormal double-contrast barium enema result? Ann Int Med 1991;114:137-41.

17 Neugut Al, Garbowski GC, Waye JD, et al. Diagnostic yield of colorectal neoplasia with colonoscopy for abdominal pain, change in bowel habits, and rectal bleeding Am J Gastroenterol 1993;88:1179-83.

18 Meineche-Schmidt V, Jørgensen T. "Alarm symptoms" in patients with dyspepsia: a threeyear prospective study from general practice. Scand J Gastroenterol 2002:37:999-1007.

19 Johanessen T, Petersen H, Kleveland PM, et al. The predictive value of history in dyspepsia. Scand J Gastroenterol 1990;25:689-97.

20 Wallace MB, Durkalski VL, Vaughan J, et al. Age and alarm symptoms do not predict endoscopic findings among patients with dyspepsia: a multicentre database study. Gut 2001;49:29-34

21 Numans ME, van der Graaf Y, de Wit NJ, et al. How useful is selection based on alarm symptoms in requesting gastroscopy? Scand J Gastroenterol 2001;36:437-43.

22 Bytzer P, Møller Hansen J, Schaffalitzky de Muckadell, et al. Predicting endoscopic diagnosis in the dyspeptic patient. The value of predictive score models. Scand J Gastroentero 1997;32:118-25.

23 Crean GP, Holden RJ, Knill-Jones RP, et al. A database on dyspepsia. Gut 1994;35: 191-202.

24 Sackett DL, Haynes RB. The architecture of diagnostic research. BMJ 2002;324:539-41. 